\title{
Produção de biomassa e conteúdo de silício em gramíneas forrageiras sob diferentes fontes de silicato
}

\section{Biomass production and silicon content in forages under different sources of silicate}

\author{
Filipe Luis Sávio; ${ }^{1}$ Gisele Carneiro da Silva ${ }^{2}$; \\ Itamar Rosa Teixeira ${ }^{3 *}$; Aluízio Borém ${ }^{4}$
}

\begin{abstract}
Resumo
Objetivou com este estudo avaliar a utilização de diferentes fontes de silício ( $\mathrm{Si}$ ) sobre as características agronômicas e conteúdos foliares de $\mathrm{Si}$ em $B$. decumbens $\mathrm{cv}$. Basilisk e P. maximum cv. Mombaça tendo como substrato o horizonte B de um Latossolo da Zona da Mata Mineira. O delineamento experimental utilizado foi o de blocos inteiramente casualizados, em esquema fatorial 4 × 2, com quatro repetições. Os tratamentos constaram de três fontes de Si (silicato de sódio, rocksil e silicato de potássio, com doses correspondentes a $40 \mathrm{~g} \mathrm{~L}^{-1}$ de $\mathrm{Si}$ ) e uma testemunha, combinadas com as duas espécies de gramíneas (B. decumbens cv. Basilisk e $P$. maximum cv. Mombaça). Conclui-se que aplicações foliares de $\mathrm{Si}$ promoveram acréscimos na produção de matéria seca de $P$. maximum no segundo e terceiro cortes. As aplicações foliares de Si proporcionaram maior absorção de silício nas duas espécies estudadas, especialmente no segundo e terceiro corte. As fontes de Si testadas (rocksil, silicato de potássio ou silicato de cálcio) não diferiram entre si, quanto à capacidade de fornecimento de Si adicionado via foliar.

Palavras-chave: Brachiaria decumbens, Panicum maximum, nutrição, micronutriente, rendimento
\end{abstract}

\begin{abstract}
The objective of this study was to evaluate the effect of sources of silicon on the agronomic traits and on Si content on B. decumbens cv. Brasilisk and P. maximum, cv. Mombaça cultivated in a B horizon soil collected from a Latosol at the "Zona da Mata Mineira", Brazil. The experimental design was a completely randomized block in a $4 \times 2$ factorial, with four replications. Treatments consisted of three sources of silicon (sodium silicate, rocksil and potassium silicate, with doses of $40 \mathrm{~g} \mathrm{~L}^{-1}$ of Si) and a control, all combined with two forage grass species (B. decumbens $\mathrm{cv}$, Basilisk and P. maximum cv. Mombaça). Results showed that Si sprayed on leaves promoted increase in dry biomass content in the second and third harvests of P. maximum. Foliar fertilization with $\mathrm{Si}$ also increased silicon absorption in both species, especially in the second and third harvests. The three silicon sources did not differ among them, as a source of silicon applied on leaves.
\end{abstract}

Key words: Brachiaria decumbens, Panicum maximum, nutrition, micronutrient, yield.

${ }^{1}$ Eng $^{\circ}$. Agro ${ }^{\circ}$, Doutorando em Melhoramento de Plantas, Escola Superior de Agricultura “Luiz de Queiroz". Av. Pádua Dias 11, Agronomia, CEP 13418-900, Piracicaba-SP. E-mail: filipe.savio@usp.br

${ }^{2}$ Eng $^{\circ}$. Agr ${ }^{\circ}$, Doutoranda em Água e Solo, Universidade Federal de Goiás. Rodovia Goiânia-Nova Veneza, Km 0, Campus Samambaia, CEP 74001-270, Goiânia-GO. E-mail: gisele.agronomia@hotmail.com

${ }^{3}$ Eng $^{\circ}$. Agr ${ }^{\circ}$, Prof. Dr. Adjunto do Departamento de Engenharia Agrícola, Universidade Estadual de Goiás, UnUCET, BR 153, Km 98, Campus Henrique Santillo, CEP 75001-970, Anápolis-GO. E-mail: itamar.texeira@ueg.br

${ }^{4}$ Eng $^{\circ}$. Agr ${ }^{\circ}$, Prof. Dr. Associado do Departamento de Fitotecnia, Universidade Federal de Viçosa. Av. P. H. Rolfs, s/n. CEP $36570-$ 000, Viçosa-MG. E-mail: gisele.agronomia@hotmail.com

* Autor para correspondência 


\section{Introdução}

O Brasil possui cerca de 100 milhões de hectares de pastagens cultivadas, muitas já com mais de 10 anos de pastejo, apresentando aproximadamente $60 \%$ das áreas em avançando estado de degradação (BARDUCCI et al., 2009). Estima-se que, a curto e em médio prazos, mais de 30 milhões de hectares necessitarão ser recuperados porque já estão degradados ou em processo acentuado de declínio de produção (SANO et al., 2008).

A maior parte das gramíneas forrageiras brasileira é constituída de capins pertencentes aos gêneros Brachiaria e Panicum, por possuírem sistema radicular vigoroso e profundo, apresentam elevada tolerância à deficiência hídrica e absorção de nutrientes em camadas mais profundas do solo, desenvolvendo-se em condições ambientais em que a maioria de outras espécies forrageiras e culturas graníferas, não se desenvolveriam.

Uma das razões da resistência das Braquiárias e dos Panicuns em solos pobres como os solos tropicais pode ser sua capacidade em absorver e acumular $\mathrm{Si}$ na epiderme das folhas, atenuando os efeitos tóxicos do alumínio, manganês, ferro e, aumentando a disponibilidade de fósforo, como ocorre em outras gramíneas (COCKER; EVANS; HODSON, 1998; KORNDÖRFER; ABDALA; BUENO, 2001). Esse acúmulo de sílica na folha reduz a transpiração e faz com que a exigência de água pelas plantas seja menor, mecanismo importante para as gramíneas que desenvolvem em solos submetidos por período de estiagem longo e severo (MELO et al., 2003).

Ademais, o silício acumulado na folha permite que esta fique mais ereta, aumentando a área foliar exposta à luz solar (EPSTEIN, 1999; CRUCIOL, 2006). Como conseqüência, outros efeitos benéficos do Si têm sido observados em várias gramíneas que o acumulam, especialmente quando estas plantas estão submetidas a estresses, bióticos e/ou abióticos (RAFI; EPSTEIN; FALK, 1997; KORNDÖRFER et al., 1999), a exemplo no aumento da produtividade, na redução da queda de folhas e na resistência a pragas e doenças (MORAES et al., 2006; PRATISSOLI et al., 2007; GOMES et al., 2008; TEIXEIRA et al., 2008). Adicionalmente, acréscimos de produtividade com a adubação silicatada já foram constatados por Korndörfer, Pereira e Camargo (2002) e Pereira et al. (2004) em outras gramíneas, como cana de açúcar e arroz. Korndörfer et al. (2010) em condições de cerrado observaram que o silicato de cálcio foi eficiente para elevar as concentrações de $\mathrm{Si}$, nas plantas de Brachiaria brizantha cv. Marandu e Panicum maximum cv. Mombaça, mas não alterou a produção de massa seca das espécies.

As espécies variam quanto ao conteúdo de $\mathrm{Si}$ presente no tecido vegetal, podendo ser classificadas em função da relação molar Si:Ca. Para relações acima de 1,0 as plantas são consideradas acumuladoras, e entre 1,0 a 0,5 são consideradas intermediárias, e menor do que 0,5 não acumuladoras (MA; MIYAKE; TAKAHASHI, 2001). Gramíneas como Braquiárias e Panicuns são classificadas como acumuladoras, ou seja, todos os benefícios atribuídos ao silício podem ser verificados com as espécies.

Os solos tropicais, em sua maioria, são altamente intemperizados, ácidos e pobres em Si disponíveis para as plantas. O calcário tem sido predominantemente utilizado para corrigir a acidez do solo mas o faz apenas na camada arável. Os silicatos, assim como os carbonatos, podem elevar o $\mathrm{pH}$ do solo, fornecer $\mathrm{Ca}$ e $\mathrm{Mg}$ e aumentar a saturação por bases, neutralizando o Al trocável (ALCARDE, 1992; DATNOFF; SNYDER; KORNDÖRFER, 2001), hipótese confirmada por Korndörfer et al. (2010), que constataram acréscimos dos valores de pH e da saturação de bases, com neutralização de alumínio tóxico em solo adubado com silicato de cálcio

A pesquisa agronômica tem buscado reduzir os custos de produção e o impacto da agricultura no meio ambiente, usando para isso, insumos menos poluentes e de baixo custo para o agricultor. 
Nesse sentido, o uso de Si pode se constituir numa alternativa importante para o manejo de pragas e doenças (MORAES et al., 2006; PRATISSOLI et al., 2007; GOMES et al., 2008; TEIXEIRA et al., 2008), com reflexos importantes para o aumento da produtividade das pastagens. Acredita-se que a adubação das pastagens com Si, além de diminuir a incidência de doenças, possa também reduzir o ataque de insetos (ex. cigarrinhas) diminuindo assim a necessidade de pesticidas. Porém, investigações sobre a capacidade de resposta de gramíneas forrageiras à diferentes fontes de adubos silicatados inexistem.

Diante do exposto, objetivou-se com este estudo avaliar a utilização de diferentes fontes de silício sobre a produção de biomassa e os conteúdos de silício absorvidos pelas gramíneas forrageiras, $B$. decumbens cv. Basilisk e P. maximum cv. Mombaça, nas condições edafoclimáticas da Zona da Mata Mineira.

\section{Material e Métodos}

O experimento foi conduzido em casa de vegetação pertencente à Universidade Federal de Viçosa (UFV), em Viçosa - MG, utilizando como substrato o horizonte B de um Latossolo Vermelho Distrófico típico, da Zona da Mata Mineira, cujas características químicas e físicas foram: $\mathrm{pH}\left(\mathrm{H}_{2} \mathrm{O}\right)$ 5,2; P $\left(\mathrm{mg} \mathrm{dm}^{-3}\right)$ 1,8; $\mathrm{K}^{+}\left(\mathrm{mg} \mathrm{dm}^{-3}\right) 42 ; \mathrm{Ca}^{2+}(\mathrm{cmol}$ $\left.\mathrm{dm}^{-3}\right) 3,2 ; \mathrm{Mg}^{2+}\left(\mathrm{cmol} \mathrm{dm}^{-3}\right) 1,1 ; \mathrm{Al}^{3+}\left(\mathrm{cmol} \mathrm{dm}^{-3}\right)$ 0,$0 ; \mathrm{H}^{+}+\mathrm{Al}^{3+}\left(\mathrm{cmol} \mathrm{dm}^{-3}\right)$ 1,0; $\mathrm{m}(\%)$ 0,0; V (\%) 52; $\mathrm{B}\left(\mathrm{mg} \mathrm{dm}{ }^{-3}\right)$ 0,5; $\mathrm{Cu}\left(\mathrm{mg} \mathrm{dm}^{-3}\right) 1,5 ; \mathrm{Fe}\left(\mathrm{mg} \mathrm{dm}^{-3}\right)$ 65,0; $\mathrm{Mn}\left(\mathrm{mg} \mathrm{dm}^{-3}\right)$ 12,2; Zn (mg dm $\left.{ }^{-3}\right)$ 1,7; Si (mg $\left.\mathrm{dm}^{-3}\right)=3,5$; matéria orgânica $\left(\operatorname{dag~kg}^{-1}\right) 1,5$; areia $(\mathrm{g}$ $\left.\mathrm{kg}^{-1}\right) 320$; silte $\left(\mathrm{g} \mathrm{kg}^{-1}\right) 35 \mathrm{e}$ argila $\left(\mathrm{g} \mathrm{kg}^{-1}\right) 145$.

$\mathrm{O}$ delineamento experimental utilizado foi $\mathrm{o}$ de blocos inteiramente casualizados, em esquema fatorial 4 x 2, com quatro repetições. Os tratamentos constaram da combinação de três fontes de $\mathrm{Si}$ (silicato de sódio, rocksil e silicato de potássio, com doses correspondentes a $40 \mathrm{~g} \mathrm{~L}^{-1}$ de $\mathrm{Si}$ ) e uma testemunha sem aplicação de $\mathrm{Si}$, combinadas com duas espécies de gramíneas forrageiras (B. decumbens cv. Basilisk e P. maximum cv. Mombaça). A quantidade de $\mathrm{Si}$, nas diferentes fontes utilizadas, pode ser observada na Tabela 1.

Tabela 1. Composição das fontes de Si utilizadas.

\begin{tabular}{lc}
\hline Fontes & Composição \\
\hline Rocksil* & $(\mathbf{S i}=\mathbf{1 7 \%}, \mathrm{Ca}=12 \%$ e K $=3 \%)$ \\
Silicato de potássio & $(\mathbf{S i}=\mathbf{2 6 \%}$ e K $=13 \%)$ \\
Silicato de sódio & $(\mathbf{S i}=\mathbf{6 3 \%}$ e Na $\mathrm{O}=18 \%)$ \\
\hline
\end{tabular}

Pó de rocha moída.

Após o sorteio, as unidades experimentais foram balanceadas com $\mathrm{CaCO}_{3}$ e $\mathrm{MgCO}_{3}$, ambos puro para análise - PA, numa relação 4:1, conforme Ribeiro, Guimarães e Alvarez (1999) para a correção do pH. O solo corrigido foi mantido incubado por um período de 45 dias, posteriormente foi realizada a adubação de base com adição de macronutrientes equivalente a $500 \mathrm{mg} \mathrm{dm}^{-3}$ de $\mathrm{N}$ na forma de sulfato de amônio, parcelado em três vezes durante o ciclo, $200 \mathrm{mg} \mathrm{dm}^{-3}$ de $\mathrm{P}_{2} \mathrm{O}_{5}$ na forma superfosfato triplo, $240 \mathrm{mg} \mathrm{dm}^{-3}$ de $\mathrm{K}_{2} \mathrm{O}$ na forma de cloreto de potássio, e adição de micronutrientes equivalente a $15,75 \mathrm{mg} \mathrm{dm}^{-3}$ de sulfato de zinco $(\mathrm{Zn}), 5,73 \mathrm{mg}$ $\mathrm{dm}^{-3}$ de bórax (B), 2,15 $\mathrm{mg} \mathrm{dm}^{-3}$ de sulfato de cobre $(\mathrm{Cu}), 1,06 \mathrm{mg} \mathrm{dm}^{-3}$ de cloreto de ferro $(\mathrm{Fe}), 0,71 \mathrm{mg}$ $\mathrm{dm}^{-3}$ de sulfato de manganês $(\mathrm{Mn})$ e $0,09 \mathrm{mg} \mathrm{dm}^{-3}$ de molibdato de sódio (Mo). 4,5 $\mathrm{dm}^{3}$ de solo foi acondicionado em vasos plásticos com capacidade de $5 \mathrm{dm}^{3}$ de solo. 
As plântulas foram obtidas pela germinação das sementes em substrato e, aos cinco dias após a emergência (DAE), foram transplantadas para os vasos num total de três plântulas por unidade experimental. As irrigações eram feitas diariamente procurando manter a umidade do solo próximo a $60 \%$ da capacidade de campo (C.C.).

Para a aplicação das fontes de Si foi utilizado um aparelho costal pressurizado com $\mathrm{CO}_{2}$, com capacidade para 20 litros. Os tratamentos via foliar receberam o surfactante, para obtenção do máximo desempenho e eficiência do produto. Durante as aplicações, foram utilizadas lonas plásticas para reduzir a deriva nas pulverizações. As aplicações foliares foram ministradas $18^{\circ} \mathrm{DAE}$ das plântulas e aos $18^{\circ}$ dias após os cortes, e sequencialmente a cada sete dias por três vezes.

Foram efetuados três cortes, aos 40, 80 e 120 DAE, ocasião em que foram avaliadas as seguintes características: produção de massa verde e seca, altura das plantas e conteúdo de Si nas folhas, seguindo a metodologia descrita por Malavolta, Vitti e Oliveira (1997).

Os dados foram submetidos à análise de variância, e quando detectada diferença entre as médias foi empregado o teste de Tukey a 5\% de probabilidade.

\section{Resultados e Discussão}

Em geral, pode-se constatar efeito diferenciado dos tratamentos efetuados nos três cortes realizados nas gramineas forrageiras. No primeiro corte constatou-se diferença somente para os conteúdos de $\mathrm{Si}$ nas folhas das gramíneas estudadas. Comportamento diferenciado foi observado a partir do segundo corte, no tocante, às características agronômicas e conteúdos foliares de Si. À exceção dos conteúdos foliares de $\mathrm{Si}$, constatados no terceiro corte das gramineas, nos demais cortes as fontes de Si testadas não promoveram alterações nas características das plantas.

Apesar de ter havido acúmulo diferenciado de Si nas folhas em função da aplicação de Si nas espécies de Braquiária e Panicum no primeiro corte, essas diferenças não foram suficientes para afetar o desenvolvimento vegetativo das forrageiras, conforme os resultados da produção das matérias fresca e seca e a altura das plantas (Tabela 2). Corroboram com estes resultados as observações de Melo et al. (2003) com B. decumbens e B. brizantha, onde relatam que a aplicação de Si no solo promoveu aumento do conteúdo desse nutriente nas folhas, mas não afetou a produção de matéria seca na fase inicial das plantas. Comportamento semelhante foi obtido por Korndörfer et al. (2010) testando Brachiaria brizantha cv. Marandu e Panicum maximum cv. Mombaça em que o fornecimento de silicato de cálcio promoveu acréscimos dos teores foliares de $\mathrm{Si}$, contudo não alterou a produção de massa seca das espécies. De acordo com os referidos autores, nos dois casos, isso em parte se deve ao fato de que as espécies, não foram submetidas ao déficit hídrico e aos ataques de pragas e doenças, a exceção dos cortes efetuados.

Para Rafi, Epstein e Falk (1997) e Korndörfer et al. (1999), o uso do silício na adubação, se manifesta positivamente, principalmente quando as plantas estão sujeitas a algum tipo de estresse, seja ele biótico ou abiótico. Nessa situação, a acumulação de $\mathrm{Si}$ nas células epidérmicas, especialmente em gramíneas, mantém as folhas mais eretas, aumentando a intensidade de luz ao longo do dossel da planta, diminuindo a transpiração, evitando ou diminuindo o estresse hídrico na folhagem e aumenta a resistência ao acamamento (EPSTEIN, 1999; CRUCIOL, 2006). Outra ação do Si, segundo Epstein (2001) é sua capacidade de aumentar o conteúdo de clorofila das folhas e a tolerância das plantas aos estresses ambientais como frio, calor, seca, desbalanço nutricional e toxicidade a metais. 
Tabela 2. Valores médios das características agronômicas e do conteúdo de Si nas folhas nas gramíneas forrageiras submetidas a diferentes fontes de silício $-1^{\circ}$ Corte.

\begin{tabular}{|c|c|c|c|c|}
\hline \multirow{3}{*}{ Fatores } & \multicolumn{3}{|c|}{ Características agronômicas } & \multirow[b]{2}{*}{$\begin{array}{c}\text { Conteúdo de } \\
\text { Silício nas Folhas }\end{array}$} \\
\hline & $\begin{array}{l}\text { Matéria } \\
\text { Fresca }\end{array}$ & $\begin{array}{l}\text { Matéria } \\
\text { Seca }\end{array}$ & Altura de Planta & \\
\hline & ................. & ${ }^{1} \ldots \ldots \ldots \ldots \ldots$ & ...................... &.. $\mathrm{mg} \mathrm{kg}^{-1} \ldots \ldots \ldots$ \\
\hline \multicolumn{5}{|l|}{ Espécies } \\
\hline Brachiaria decumbens & 23,28 & 3,80 & 39,94 & $0,91 \mathrm{a}$ \\
\hline Panicum maximum & 20,66 & 3,86 & 44,94 & $0,71 \mathrm{~b}$ \\
\hline \multicolumn{5}{|l|}{ Fontes de Silício } \\
\hline Rocksil & 21,91 & 3,53 & 41,38 & 0,82 \\
\hline Silicato de Potássio & 20,56 & 3,40 & 41,50 & 0,90 \\
\hline Silicato de Sódio & 24,89 & 4,17 & 43,88 & 0,74 \\
\hline Testemunha & 20,53 & 4,20 & 42,00 & 0,78 \\
\hline Média & 21,97 & 3,83 & 42,27 & 0,81 \\
\hline C.V. $(\%)$ & 28,88 & 22,27 & 13,16 & 25,01 \\
\hline
\end{tabular}

Médias seguidas pela mesma letra na coluna diferem estatisticamente entre si, pelo teste de Tukey a $5 \%$ de probabilidade.

Baseado no pressuposto de que a essencialidade de um nutriente pode ser atribuída ao decréscimo da resistência a qualquer fator estressante (EXLEY, 1998), pode-se dizer que silício se enquadra dentro desta definição, uma vez que a carência pode promover redução da capacidade da plantas em resistir às condições adversas do meio (RAFI; EPSTEIN; FALK, 1997).

A partir do primeiro corte, as diferenças entre os tratamentos ficaram mais nítidas, confirmadas pela diferenças de matéria fresca e seca produzidas, na altura das plantas e no o conteúdo de Si nas folhas dos capins Braquiária e Panicum no segundo corte (Tabela 3), repetindo a mesma comportamento no terceiro corte (Tabela 4). As aplicações do Si foliar propiciaram ao P. maxium cv. Mombaça acréscimos superiores, da produção da matéria seca no segundo e terceiro cortes, respectivamente, de $14 \%$ e $15 \%$ (Tabelas 3 e 4), comparativamente à $B$. decumbens $c v$. Basilisk. A submissão das plantas às condições estressantes como os cortes, pode ter influenciado nesses resultados, conforme sugerem Korndörfer, Abdala e Bueno (2001), que obtiveram incremento da produção de matéria seca de $B$. decumbens em $17 \%$ com a aplicação do silicato de cálcio na dose de $2000 \mathrm{~kg} \mathrm{ha}^{-1}$, tendo a capacidade de resposta se acentuado com o ciclo.

As duas espécies forrageiras testadas, diferiram quanto ao acúmulo de Si na parte áerea, tendo $B$. decumbens apresentado maiores valores nos três cortes (Tabelas 2, 3 e 4), quando comparado com P. maximum, isso se deve, provavelmente ao "efeito diluição" dos nutrientes, em virtude do acréscimo na produção de matéria seca obtida para a segunda espécie com a aplicação da fertilização silicatada, notadamente no segundo e terceiro cortes, hipótese condizente com Malavolta, Vitti e Oliveira (2007). Menores conteúdos de Si na parte aérea de $B$. brizantha comparativamente a $B$. decumbens foram obtidos por Melo et al. (2003), e que corrobora a hipótese supracitada, ou seja, de que os conteúdos de nutrientes na planta por "efeito diluição" decrescem em função dos acréscimos de biomassa. 
Tabela 3. Valores médios das características agronômicas e do conteúdo de Si nas folhas nas gramíneas forrageiras submetidas a diferentes fontes de silício $-2^{\circ}$ Corte.

\begin{tabular}{|c|c|c|c|c|}
\hline \multirow[b]{3}{*}{ Fatores } & \multicolumn{3}{|c|}{ Características agronômicas } & \multirow{2}{*}{$\begin{array}{c}\text { Conteúdo de } \\
\text { Silício nas Folhas }\end{array}$} \\
\hline & Matéria Fresca & Matéria Seca & Altura de Planta & \\
\hline & \multicolumn{2}{|c|}{.................... g vaso $^{-1} \ldots \ldots \ldots \ldots \ldots . . . . . . .}$. & ...................... & ......mg kg-1....... \\
\hline \multicolumn{5}{|l|}{ Espécies } \\
\hline Brachiaria decumbens & $21,71 \mathrm{a}$ & $3,22 \mathrm{~b}$ & $32,94 \mathrm{~b}$ & $1,45 \mathrm{a}$ \\
\hline Panicum maximum & $19,87 \mathrm{~b}$ & $3,66 \mathrm{a}$ & $37,25 \mathrm{a}$ & $1,06 \mathrm{~b}$ \\
\hline \multicolumn{5}{|l|}{ Fontes de Silício } \\
\hline Rocksil & 20,27 & 3,17 & 34,63 & $1,42 \mathrm{a}$ \\
\hline Silicato de Potássio & 20,97 & 3,61 & 36,50 & $1,12 \mathrm{~b}$ \\
\hline Silicato de Sódio & 22,20 & 3,59 & 32,50 & $1,24 \mathrm{ab}$ \\
\hline Testemunha & 19,73 & 3,37 & 36,75 & $1,26 \mathrm{ab}$ \\
\hline Média & 20,79 & 3,44 & 35,10 & 1,26 \\
\hline C.V. $(\%)$ & 11,03 & 12,76 & 11,35 & 11,29 \\
\hline
\end{tabular}

Médias seguidas pela mesma letra na coluna diferem estatisticamente entre si, pelo teste de Tukey a $5 \%$ de probabilidade.

Tabela 4. Valores médios das características agronômicas e do conteúdo de Si nas folhas nas gramíneas forrageiras submetidas a diferentes fontes de silício $-3^{\circ}$ Corte.

\begin{tabular}{|c|c|c|c|c|}
\hline \multirow{3}{*}{ Fatores } & \multicolumn{4}{|c|}{ Características agronômicas } \\
\hline & Matéria Fresca & Matéria Seca & Altura de Planta & $\begin{array}{c}\text { Conteúdo de Silício nas } \\
\text { Folhas }\end{array}$ \\
\hline & ................... & $\mathrm{o}^{-1} \ldots \ldots \ldots \ldots \ldots \ldots$ & ....................... & $\ldots \ldots \mathrm{mg} \mathrm{kg}^{-1} \ldots \ldots$. \\
\hline \multicolumn{5}{|l|}{ Espécies } \\
\hline Brachiaria decumbens & $8,50 \mathrm{a}$ & $1,26 \mathrm{~b}$ & $24,51 \mathrm{a}$ & $1,57 \mathrm{a}$ \\
\hline Panicum maximum & $7,96 \mathrm{~b}$ & $1,45 \mathrm{a}$ & $15,04 \mathrm{~b}$ & $1,39 \mathrm{~b}$ \\
\hline \multicolumn{5}{|l|}{ Fontes de Silício } \\
\hline Rocksil & 8,36 & 1,42 & 19,45 & 1,39 \\
\hline Silicato de Potássio & 9,19 & 1,45 & 21,78 & 1,66 \\
\hline Silicato de Sódio & 7,95 & 1,33 & 18,92 & 1,47 \\
\hline Testemunha & 7,43 & 1,23 & 18,95 & 1,40 \\
\hline Média & 8,23 & 1,36 & 19,78 & 1,48 \\
\hline C.V. $(\%)$ & 17,06 & 16,50 & 10,71 & 14,04 \\
\hline
\end{tabular}

Médias seguidas pela mesma letra na coluna, diferem estatisticamente entre si, pelo teste de Tukey a $5 \%$ de probabilidade.

Os conteúdos médios de $\mathrm{Si}$, encontrados nos três cortes, da parte aérea das gramíneas $B$. decumbens e $P$. maximum submetidas às três fontes de $\mathrm{Si}$ foram respectivamente de 0,$81 ; 1,26$ e $1,48 \mathrm{mg}$ $\mathrm{kg}^{-1}$ (Tabelas 2, 3 e 4) assim, próximos aos valores obtidos por Melo et al. (2003) com B. decumbens $\left(\mathrm{mg} \mathrm{kg}^{-1}\right)$ em três épocas de corte. Contudo, ressaltase que segundo Korndörfer et al. (1999), Korndörfer, Pereira e Camargo (2002), no Brasil ainda não há na literatura valores de referência para se estabelecer faixas de suficiência, deficiência e toxidez para as plantas.

As aplicações foliares de Si aumentou linearmente a concentração média de Si na parte aérea das duas espécies $B$. decumbens e $P$. maximum nos três cortes (Tabelas 2, 3 e 4), corroborando com os resultados de Pereira et al. (2004), em que os autores afirmam que existe uma estreita relação entre os conteúdos foliares e a dose de silício aplicada. Nesse contexto, observa-se que os conteúdos de Si nas folhas quase 
que dobrou quando se compara aos valores obtidos no primeiro, segundo e terceiro corte de ambas as forrageiras, mostrando a eficácia da adubação foliar em promover acréscimo do nutriente em questão. A ausência de resposta das forrageiras às fontes utilizadas de Si sugere que qualquer uma das fontes pode ser utilizada na fertilização silicatada, para as duas espécies estudadas.

\section{Conclusões}

1. As aplicações foliares de $\mathrm{Si}$ promovem no segundo e terceiro cortes maior produção de massa seca para as duas espécies estudadas;

2. Há maior absorção de Si pela Brachiaria decumbens cv. Basilisk com aplicações foliares de $\mathrm{Si}$;

3. Para Panicum maximum cv. Mombaça, a maior absorção de $\mathrm{Si}$, via aplicação foliar se dá no segundo e terceiro cortes;

4. As fontes de Si testadas tiveram a mesma capacidade de fornecer Si via foliar.

\section{Agradecimentos}

Ao CNPq pela concessão da bolsa PIBIC ao primeiro autor e ao Departamento de Fitotecnia da UFV por ter fornecido todas as condições para condução dos trabalhos.

\section{Referências}

ALCARDE, J. C. Corretivos da acidez dos solos: características e interpretações técnicas. São Paulo: ANDA, 1992. 62 p. (Boletim Técnico, 6).

BARDUCCI, R. S.; COSTA, C.; CRUSCIOL, C. A. C.; BORGHI, É.; PUTAROV, T. C.; SARTI, L. M. N. Produção de Brachiaria brizantha e Panicum maximum com milho e adubação nitrogenada. Archivos de Zootecnia, Córdoba, v. 58, n. 222, p. 211-222, 2009.

COCKER, K. M.; EVANS, D. E.; HODSON, M. J. The amelioration of aluminium toxicity by silicon in higher plants: solutions chemistry or in plant mechanism?
Physiologia Plantarum, Copenhagen, v. 104, n. 4, p. 608614, 1998.

CRUCIOL, C. A. C. Silício para as gramíneas forrageiras. Revista Campo e Negócios, Uberlândia, v. 4, n. 1, p. 1415, 2006.

DATNOFF, L. E.; SNYDER, G. H.; KORNDÖRFER, G. H. Silicon in agriculture. Amsterdam: Elsevier, 2001. $424 \mathrm{p}$.

EPSTEIN, E. Silicon in plants: facts vs concepts. In: DATNOFF, L. E.; SNYDER, G. H.; KORNDÖRFER, G. H. (Ed.). Silicon in agriculture. The Netherlands:Elsevier Science, 2001. p. 1-15.

. Silicon. Annual Review of Plant Physiology and Molecular Biology, Palo Alto, v. 50, n. 6, p. 641-664, 1999.

EXLEY, C. Silicon in life: a bioinorganic solution to bioorganic essentially. Journal of Inorganic Biochemistry, New York, v. 69, n. 3, p. 139-144, 1998.

GOMES, F. B.; MORAES, J. C.; SANTOS, C. D.; ANTUNES, C. S. Uso de silício como indutor de resistência em batata a Myzus persicae (Sulzer) (Hemiptera: Aphididae). Neutropical Entomology, Piracicaba, v. 37, n. 2, p. 185-190, 2008.

KORNDÖRFER, C. M.; ABDALA, A. L.; BUENO, I. C. S. O silício e as gramíneas no cerrado. Veterinária Notícias, Uberlândia, v. 7, n. 1, p. 153-163, 2001.

KORNDÖRFER, G. H.; COELHO, N. M.; SNYDER, D. H.; MIZUTANI, C. T. Avaliação de métodos de extração de silício para solos cultivados com arroz de sequeiro. Revista Brasileira de Ciência do Solo, Viçosa, v. 23, n. 1, p. 101-103, 1999.

KORNDÖRFER, G. H.; PEREIRA, H. S.; CAMARGO, M. S. Papel do silício da produção de cana-de-açúcar. STAB Açúcar e Álcool e Subprodutos, Piracicaba, v. 21, n. 1, p. 6-9, 2002.

KORNDÖRFER, P. H.; SILVA, G. C.; TEIXEIRA, I. R.; SILVA, A. G.; FREITAS, R. S. Efeito da adubação silicatada sobre gramíneas forrageiras e características químicas do solo. Pesquisa Agropecuária Tropical, Goiânia, v. 40, n. 2, p. 119-125, 2010.

MA, J. F.; MIYAKE, Y.; TAKAHASHI, E. Silicon as a benefical element for crop plants. In: DATNOFF, L. E.; SNYDER, G. H.; KORNDÖRFER, G. H. Silicon on agriculture. Amsterdam: Elsevier, v. 8, cap.2, p. 17-39. 2001.

MALAVOLTA, E.; VITTI, G. C.; OLIVEIRA, S. A. Avaliação do estado nutricional das plantas: princípios e aplicações. 2. ed. Piracicaba: Potafós, 1997. 319 p. 
MELO, S. P.; KORNDÖRFER, G. H.; KORNDÖRFER, C. M.; LANA, R. M. Q.; SANTANA, D. G. Silicon accumulation and water deficit tolerance in brachiaria grass. Scientia Agricola, Piracicaba, v. 60, n. 4, p. 755759, 2003.

MORAES, S. R. G.; POZZA, E. A.; ALVES, A.; POZZA, A. A. A.; CARVALHO, J. G.; LIMA, P. H.; BOTELHO, A. O. Efeito de fontes de silício na incidência e na severidade da antracnose do feijoeiro. Fitopatologia Brasileira, Brasília, v. 31, n. 1, p. 69-75, 2006.

PEREIRA, H. S.; KORNDÖRFER, G. H.; VIDAL, A. A.; CAMARGO, M. S. Silicon sources for rice crop. Scientia Agrícola, Piracicaba, v. 65, n. 5, p. 522-528, 2004.

PRATISSOLI, D.; ALMEIDA, G. D.; JESUS JÚNIOR, W. C.; VICENTINI, V. B.; HOLTZ, A. M.; COCHETO, J. G. Fertilizante organomineral e argila silicatada como indutores de resistência á varíola do mamoeiro. Idesia, Arica, v. 25, n. 2, p. 63-67, 2007.
RAFI, M. M.; EPSTEIN, E.; FALK, R. H. Silicon deprivation causes physical abnormalities in wheat (Triticum aestivum L.). Journal of Plant Physilogy, Stuttgart, v. 151, n. 4, p. 497-501, 1997.

RIBEIRO, A. C.; GUIMARÃES, P. T. G.; ALVAREZ, V. V. H. (Ed.). Recomendações para o uso de corretivos e fertilizantes em Minas Gerais - $5^{\circ}$ Aproximação. Viçosa: CFSEMG, $1999.510 \mathrm{p}$.

SANO, E. E.; ROSA, R.; BRITO, J. L. S.; FERREIRA, L. G. Mapeamento semidetalhado do uso da terra no bioma Cerrado. Pesquisa Agropecuária Brasileira, Brasília, v. 43, n. 1, p. 153-156, 2008.

TEIXEIRA， I. R.; SILVA， R. P.; SILVA，A. G.; KORNDORFER, P. H. Fontes de silício em cultivares de feijão nas safras das "águas" e "seca". Revista Ciência Agronômica, Fortaleza, v. 39, n. 3, p. 562-568, 2008. 